\title{
Prefecture-level economic conditions and risk of suicide in Japan: a repeated cross-sectional analysis 1975-2010
}

\section{Citation}

Suzuki, E., S. Kashima, I. Kawachi, and S. V. Subramanian. 2014. "Prefecture-Level Economic Conditions and Risk of Suicide in Japan: A Repeated Cross-Sectional Analysis 1975-2010." The European Journal of Public Health 24 (6): 949-54. https://doi.org/10.1093/eurpub/cku023.

\section{Permanent link}

http://nrs.harvard.edu/urn-3:HUL.InstRepos:41288306

\section{Terms of Use}

This article was downloaded from Harvard University's DASH repository, WARNING: This file should NOT have been available for downloading from Harvard University's DASH repository.

\section{Share Your Story}

The Harvard community has made this article openly available.

Please share how this access benefits you. Submit a story.

\section{Accessibility}


European Journal of Public Health, Vol. 24, No. 6, 949-954

(C) The Author 2014. Published by Oxford University Press on behalf of the European Public Health Association. All rights reserved. doi:10.1093/eurpub/cku023 Advance Access published on 7 March 2014

\title{
Prefecture-level economic conditions and risk of suicide in Japan: a repeated cross-sectional analysis 1975-2010
}

\author{
Etsuji Suzuki ${ }^{1}$, Saori Kashima ${ }^{2}$, Ichiro Kawachi ${ }^{3}$, S. V. Subramanian ${ }^{3}$ \\ 1 Department of Epidemiology, Graduate School of Medicine, Dentistry and Pharmaceutical Sciences, Okayama \\ University, Okayama, Japan \\ 2 Department of Public Health and Health Policy, Institute of Biomedical \& Health Sciences, Hiroshima University, \\ Hiroshima, Japan \\ 3 Department of Social and Behavioral Sciences, Harvard School of Public Health, Boston, MA, USA
}

Correspondence: Etsuji Suzuki, 2-5-1 Shikata-cho, Kita-ku, Okayama 700-8558, Japan, Tel: +81 86235 7174, Fax: +81 86235 7178, e-mail: etsuji-s@cc.okayama-u.ac.jp

\begin{abstract}
Background: Geographical inequalities in suicide have risen dramatically across 47 prefectures in Japan since 1995. We sought to examine temporal changes in the associations between prefecture-level economic conditions and completed suicide during the recent 35 years, controlling for individual composition in each prefecture. Methods: Based on quinquennial vital statistics and census data from 1975 to 2010, we analysed the entire population aged 25-64 years. The total number of suicides was 87553 men and 34559 women. As indicators of prefecture-level economic conditions, we used average yearly income, average savings and income inequality (measured by Gini coefficients for yearly income). For each sex, we estimated odds ratios and $95 \%$ credible intervals for suicide using multilevel logistic regression models, with cells at level 1, years at level 2 and prefectures at level 3. Results: Even after adjusting for individual age, occupation and time trends, low average savings at prefecture level were associated with a higher risk of suicide among men (odds ratio in low vs. high savings: $1.13,95 \%$ credible interval: 1.05-1.21), whereas no clear patterns were observed with other economic indicators. When we further examined the associations in year-specific models by conducting a two-level analysis, both average yearly income and average savings were inversely associated with suicide risk in recent years. No clear association was found between income inequality and suicide risk for either sex. Conclusion: The present findings suggest that low area socioeconomic status may be driving the growing geographical inequalities in suicide in Japan, primarily among men.
\end{abstract}

\section{Introduction}

uicide is a major public health problem worldwide, ${ }^{1}$ and this

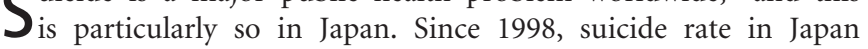
$(\sim 24$ per 100000) has been considerably higher than the world average ( 16 per 100000$)$. As originally recognized by Durkheim, ${ }^{2}$ suicide is shaped by social forces as well as individual characteristics. ${ }^{3}$ Previous studies have suggested a range of factors associated with suicide that relate to distal as well as more proximal causes along a hypothetical aetiological pathway to suicide. ${ }^{4-9}$ Given this complex, multidimensional aetiology, there is an interest in investigating inequalities in suicide in terms of individual socioeconomic position as well as varying social contexts.

At the contextual level, socioeconomic conditions seem to be strongly associated with suicide in Asian countries. ${ }^{7}$ A systematic review of the association between suicide and socioeconomic characteristics of geographical areas showed that studies from Asian countries, compared with research from the West, were more likely to have found a significant association between adverse socioeconomic conditions and increased suicide rates. ${ }^{10}$ For example, an ecological study from Japan, which examined causespecific mortality differences across socioeconomic position of municipalities, showed that socioeconomic inequalities in regional mortality of suicide increased from 1973-77 to 1993-98 in both sexes. ${ }^{11}$ Despite the cumulative evidence of an inverse association between area socioeconomic position and area suicide rates, however, it is necessary to tease apart area-level associations into its constituent compositional effects vs. contextual effects (or attributes of the physical structure and social relations within those areas). ${ }^{10,12}$ Thus, the evidence so far does not necessarily implicate any contextual effects of the area over and above the characteristics of residents.

A recent study from Japan showed a striking temporal change in the pattern of social inequalities in suicide among men and that geographical inequalities in suicide have considerably increased across 47 prefectures, primarily among men, since $1995 .{ }^{13}$ It remains unclear, however, what is driving the growing geographical inequalities in the nation. In this study, we sought to examine temporal changes in the associations between prefecture-level economic conditions and completed suicide, controlling for individual composition in each prefecture. We hypothesized that there are growing contextual effects of area socioeconomic conditions on suicide risk, which contributed to a corresponding change to the widening geographical inequalities in suicide in the nation.

\section{Methods}

\section{Data}

Suicide mortality data were obtained from the 'Report of Vital Statistics: Occupational and Industrial Aspects', ${ }^{14}$ which is compiled by the Ministry of Health, Labour and Welfare every 5 years, coinciding with the Population Census. Cause-specific mortality data have been available since 1975 . In the death notifications, respondents are asked to fill in the decedent's occupation at the time of death. ${ }^{15}$ In the Vital Statistics, suicide was coded according to the International Classification of Disease (ICD) as 
follows: ICD-8 codes: E950-E959 in 1975; ICD-9 codes: E950-E959 in 1980 to 1990 and ICD-10 codes: X60-X84 in 1995-2010. Occupation at the time of death is recorded for each decedent following the Japan Standard Occupational Classification. ${ }^{16}$ During the study period, the occupational classification scheme underwent five revisions (Supplementary table S1). In this study, we used the fourth revision of the Occupational Classification, which includes the following 11 groups: (i) specialist and technical workers, (ii) administrative and managerial workers, (iii) clerical workers, (iv) sales workers, (v) service workers, (vi) security workers, (vii) agriculture, forestry and fishery workers, (viii) transport and communication workers, (ix) production process and related workers, (x) workers not classifiable by occupation and (xi) non-employed. (A full description of each occupational group is available on-line. ${ }^{16}$ ) Note that the group 'non-employed' includes the unemployed as well as the non-labour force (e.g. homemakers, students and the retired). We restricted the analysis to those who are aged 25-64 years to exclude students and the retired. The total number of suicides was 87553 men and 34599 women (Supplementary table S2).

Denominator data for the calculation of suicide rates were obtained from the Population Census that has been conducted by the Ministry of Internal Affairs and Communications every 5 years since $1920 .{ }^{17}$ In the Census questionnaire, occupation is assessed by the following question: ${ }^{17}$ 'Description of work-Describe in detail the duties you are assigned to perform'. One questionnaire is delivered to every household, and one person in each household completes it on behalf of the household members. We used 'production process and related workers' as the referent category because they were the largest occupational category across the majority of the time periods (Supplementary table S3).

For each of the 47 prefectures, we measured two economic conditions-average economic well-being and dispersion. These conditions have been often used in previous studies of the association between suicide and socioeconomic characteristics of geographical areas. ${ }^{10}$ By using the 'National Survey of Family Income and Expenditure', ${ }^{18}$ which has been conducted by the Ministry of Internal Affairs and Communications every 5 years since 1959, we obtained three prefecture-level variables; average yearly income and average savings were used to measure average economic well-being, while Gini coefficient for yearly income was used to measure economic dispersion (Supplementary table S4 and Supplementary Figures S1-S3). These variables were calculated among two-ormore-person households (including children). We decided to use these variables because they are the only available indicators throughout the study period. The Gini coefficient for yearly income has only been available since 1979; therefore we imputed the values of 1979 to 1974 . We linked the data set of prefecture-level variables to the data set of the Population Census and the Vital Statistics one year out, e.g. National Survey of Family Income and Expenditure in 2009 was linked with the Population Census in 2010 and the Vital Statistics in the 2010 fiscal year.

\section{Analysis}

The data had a three-level structure of 33012 cells for men and 32979 cells for women at level 1, nested within 8 years at level 2, which were nested within 47 prefectures at level 3 . The 8 years comprised 1975, 1980, 1985, 1990, 1995, 2000, 2005 and 2010. Each year had a maximum of 88 cells ( 8 5-year age groups $\times 11$ occupational groups). Note that the number of suicides in each cell was recorded during one fiscal year (which in Japan runs from April to the end of March of the following year).

We employed multilevel statistical procedures because of their ability to model complex variance structures at multiple levels. ${ }^{19}$ The unit of analysis was 'cells', and our models were structurally identical to models with individuals at level $1 .{ }^{20}$ The response variable, proportion of suicide deaths in each cell, was modelled with allowances made for the varying denominator in each cell.

First, we conducted a three-level analysis as an overall model for each sex, with cells at level 1 , years at level 2 , and prefectures at level 3 . In this model, the prefecture-level economic condition for each year was entered as a level 2 variable separately, which allows us to examine the associations between prefecture-level variables and suicide risk while adjusting for individual age, occupation and time trends. The prefecture-level variance was used as an estimate of geographical inequalities in suicide. The importance of measures of between-area variation has been emphasized for a better understanding of the socio-spatial patterning of health. ${ }^{21-24}$ Subsequently, to examine possible temporal changes in the associations between prefecture-level variables and suicide risk, we also conducted a twolevel analysis, with cells at level 1 and prefectures at level 2 for each year separately. As a sensitivity analysis, we simultaneously entered average yearly income/savings and Gini coefficients into the overall and year-specific models.

To fit multilevel binomial logit link models, we used Bayesian estimation procedures as implemented via Markov chain Monte Carlo methods by using MLwiN 2.27.25,26 We used default diffuse priors for all the parameters. We obtained maximum likelihood estimates for starting values of the distribution, then 500 simulations as discarded burn-in, then 50000 further simulations to get the distribution of interest. Based on the mean as well as the 2.5th and 97.5th percentiles of the posterior distributions, odds ratios (ORs) and 95\% credible intervals (CIs) for suicide were obtained. With regard to prefecture-level variance, we calculated median ORs (MORs). ${ }^{27}$ The MOR is always $\geq 1$. If the MOR is 1 , there is no variation between prefectures. If there is considerable betweenprefecture variation, the MOR will be large. The measure is directly comparable with fixed effects ORs. A $P$-value of $<0.05$ (two-sided) was considered statistically significant.

\section{Results}

Table 1 shows the results of sex-stratified associations between prefecture-level economic conditions and suicide risk, adjusting for individual age, occupation and time trends. Among men, average savings at prefecture level were inversely associated with suicide risk in the overall model (OR in low vs. high savings: 1.13, 95\% CI 1.05-1.21). No clear patterns were observed for the other variables. Among women, we found no clear associations between prefecture-level economic conditions and suicide risk.

When we further examined the associations in year-specific models, however, we found a remarkable increase in the associations between prefecture-level average income/savings and suicide risk among men. Although average savings were not associated with suicide risk in 1975, an inverse association emerged in 1980, followed by a steady strengthening of the association until 2005 (especially since 1995). The association was attenuated in 2010. We found a similar pattern between average yearly income and suicide risk among men. In women, we also found that both average income/savings were inversely associated with suicide risk for most of the period since 1985. Overall, however, the findings for women were less consistent than those for men and we did not observe significant associations in 2005 or 2010. In both sexes, we found no clear association between Gini coefficients and suicide risk throughout the study period. When we simultaneously adjusted for Gini coefficients and average income/savings, no substantial changes were observed (data not shown).

In table 2, we show MORs from the overall model and the yearspecific models. Even after adjusting for individual age and occupation, we observed a remarkable increase in geographical inequalities in suicide among men. Including average savings as a covariate somewhat reduced the MORs. Among women, the increasing trend in geographical inequalities was less clear and we 


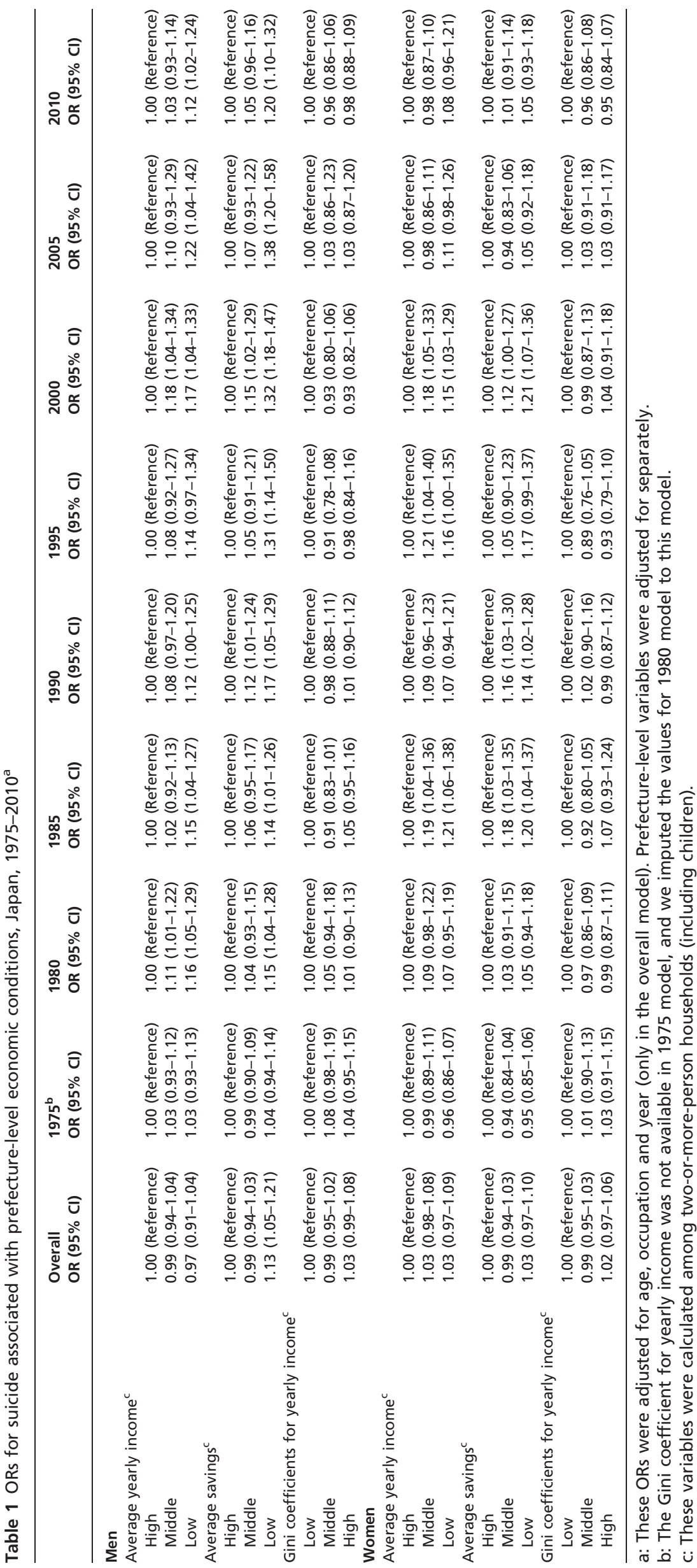


observed rises and falls of the MORs, including two spikes in 1985 and 1995. Unlike men, even when adjusting for prefecture-level variables, we observed no substantial changes in MORs. When we simultaneously adjusted for Gini coefficients and average income/savings, the results were similar to those of the corresponding models without adjusting for the Gini coefficients (data not shown).

\section{Discussion}

By applying the novel multilevel methods, we examined the associations between two prefecture-level economic conditions and suicide risk from 1975 to 2010 in Japan, while adjusting for varying individual composition in each prefecture. To provide a comprehensive perspective, the data of this study are census based and cover the whole of Japan. The present findings suggest that average savings at the prefecture level are inversely associated with suicide risk among men, even after adjusting for individual age, occupation and time trends. In contrast, no clear patterns were observed with average income or income inequalities. Meanwhile, among women, we found no clear associations between prefecture-level economic conditions and suicide risk in the overall model.

Notably, we found dramatic changes in the associations between prefecture-level average income/savings and suicide risk throughout the study period, while adjusting for individual occupation by using the consistent classification. Although these collective material resources of an area were not associated with suicide risk among men in 1975, inverse associations emerged in 1980, followed by steady strengthening of the association until 2005 (especially since 1995). At the same time, we also found a notable widening of geographical inequalities in suicide among men, especially since 1995. Thus, the present findings suggest that among men, the link between low area socioeconomic status and suicide risk preceded the emergence of geographical inequalities in suicide by $\sim 15$ years. A previous study from Japan showed that, while adjusting for individual age and occupation, all six prefectures in the Tohoku region (the northeastern region of the main island of Honshu) and Niigata prefecture (a neighbouring prefecture to the Tohoku region) have the highest suicide risk, whereas some prefectures in the Kanto, Kinki and Chugoku regions (central or western districts of the main island) have the lowest suicide risk. ${ }^{13}$ Overall, the economic conditions of the predominantly rural areas in the region may be characterized by population decline, population ageing and lower per capita income. ${ }^{17,28}$ We thus a posteriori hypothesize that the contextual effect of low socioeconomic characteristics of areas on suicide is (at least partially) a driving force behind the growing east-west inequalities in suicide of the nation.

Among women, we found that both average income/savings were inversely associated with suicide risk for most of the period since 1985 (i.e. 5 years behind men). Overall, however, the findings for women were less consistent than those for men, implying that the contextual effect of area socioeconomic characteristics on suicide could be limited among women in terms of magnitude and duration. This finding may explain the less prominent increase of geographical inequalities in suicide among women. Our findings suggest that the degree of geographical inequalities among women only slightly increased in 1985 (i.e. after the second economic crisis of 1980-83) and 1995 (i.e. after the collapse of the asset bubble in the early 1990s).

We used prefecture-level income inequality as a measure of the scale of social stratification ${ }^{29}$ and found no clear associations with suicide in either sex. Although most studies have reported no association between income inequalities and suicide risk, ${ }^{10}$ two ecological studies from Japan reported that, unlike other OECD countries, national-level income inequality increases suicide risk in Japan, suggesting that temporal fluctuations in the suicide rate can be partly explained by an increase in income inequality. ${ }^{30,31}$ Our 
findings, however, suggest that these previous findings from Japan are more likely to be a rediscovery of the relationship between income and suicide.

We should note that the measures of prefecture-level economic conditions in this study provide only truncated information about the context of areas. ${ }^{32}$ As has been noted, ${ }^{10}$ the association between area socioeconomic characteristics and suicide could differ depending on the socioeconomic measures. More importantly, although a recent paper from Japan implied that occupation is a strong determinant of the suicide risk, ${ }^{13}$ we lacked information at the individual level on the socioeconomic variables measured at the prefecture level, i.e. household income and household savings. Therefore, we cannot fully rule out the possibility that the present findings reflect the emerging associations between individual-level socioeconomic status and suicide risk throughout the study period. If the assumption that the confounding structure has not changed over time is violated, a careful interpretation is needed when comparing ORs across models. On a related issue, there is a possibility that excluding single-person households underestimates the true extent of income inequality. Despite the variation in the share of single-person households across prefectures, however, we believe that this does not substantially influence our conclusions because we used tertiles of prefecture-level economic conditions in the analysis.

There are other limitations of this study. First, the smallest geographical unit available was the prefecture, and we could not explore some potential contextual processes that operate at smaller level of aggregation. Further analysis using different area units would lead to a better understanding of the causal processes involved in the potential contextual effect(s) on suicide-if suicide mortality is strongly dependent on characteristics of the immediate physical and social environment as well as psychological and behavioural attributes, then contextual factors of smaller area units would be more desirable, e.g. social capital. ${ }^{33-35}$ In contrast, the prefecture may be a useful and valid unit of analysis because it has direct administrative authority over the economic, education and health sectors. ${ }^{36}$ Furthermore, the prefecture has specific jurisdiction over health centres, which are the loci of preventive health care activity. ${ }^{36}$

Second, there are concerns about the quality of cause-of-death coding and the completeness of the ascertainment of suicide cases. ${ }^{37}$ However, death registration is mandatory in Japan and all death certificates are signed by medical doctors. If the death is certified as a suicide, the police must be notified and suspected suicides need to be examined by a qualified medical pathologist. All death certificates are sent to the Ministry of Health, Labour and Welfare and coded for National Vital Statistics. Thus, we believe that the quality and completeness of suicide mortality data in this study are reliable. Indeed, the quality of mortality data in Japan is rated as level 1 (best quality) by the Department of Measurement and Health Information of the World Health Organization. ${ }^{38}$ Besides, considering that the numbers of deaths classified as undetermined intent were relatively low (Supplementary table S5), the present findings are less likely to be influenced by misclassified suicides.

Third, we should note that this study findings do not necessarily apply to the pattern of inequalities in parasuicide or suicidal ideation. It is important to realize that despite some similarities, ${ }^{39}$ suicide attempters and completers in Japan would have significant demographic, personality and clinical differences. ${ }^{40}$ Previous suicide attempts or deliberate self-harm are regarded as very important risk factors for completed suicide ${ }^{9}$ and thus, from a perspective of preventive medicine, it would be beneficial to examine the trends in parasuicide and suicidal ideation within the nation.

Finally, we restricted the analysis to those who are aged 25-64 years to exclude students and the retired. Although we used the data about occupation at the time of death, this may not necessarily reflect the individual's life-course socioeconomic position.
These findings suggest that emerging contextual processes associated with low area socioeconomic status are driving forces behind the growing geographical inequalities in suicide in Japan (primarily among men). In contrast, economic dispersion does not apparently influence the risk of suicide mortality in either sex. Indeed, the influence of individual social class on the risk of suicide cannot be overemphasized. ${ }^{12}$ Considering the growing contextual effects of area socioeconomic characteristics, however, suicide prevention resources should focus more on communities of a relatively lower socioeconomic level.

\section{Supplementary data}

Supplementary data are available at EURPUB online.

\section{Acknowledgements}

The authors thank Akiko Tokinobu for her assistance with data collection. The authors are also grateful to Eiji Yamamoto for his statistical advice on revising the manuscript.

\section{Funding}

This work was supported by The Okayama Medical Foundation and Grant-in-Aid for Scientific Research, Ministry of Education, Culture, Sports, Science and Technology (MEXT), Japan. SVS was supported by a Robert Wood Johnson Investigator Award in Health Policy Research.

Conflicts of interest: None declared.

\section{Key points}

- Previous studies have suggested a range of factors associated with suicide that relate to distal as well as more proximate causes along a hypothetical aetiological pathway to suicide. However, the cumulative evidence does not necessarily imply the contextual effects of the area over and above the characteristics of residents.

- Even after controlling for individual age and occupation, low area socioeconomic status is associated with higher risk of suicide in recent years, primarily among men, whereas economic dispersion is not associated with suicide risk in either sex.

- Considering the growing contextual effects of area socioeconomic characteristics, suicide prevention resources should focus more on communities of a relatively lower socioeconomic level.

\section{References}

1 Windfuhr K, Kapur N. International perspectives on the epidemiology and aetiology of suicide and self-harm. In: O'Connor RC, Platt S, Gordon J, editors. International Handbook of Suicide Prevention: Research, Policy and Practice. Malden, MA: John Wiley \& Sons, 2011: 27-57.

2 Durkheim E. Suicide: A Study in Sociology. Glencoe, IL: The Free Press, 1951.

3 Knox KL, Conwell Y, Caine ED. If suicide is a public health problem, what are we doing to prevent it? Am J Public Health 2004;94:37-45.

4 Maris RW. Suicide. Lancet 2002;360:319-26.

5 Nock MK, Borges G, Bromet EJ, et al. Suicide and suicidal behavior. Epidemiol Rev 2008;30:133-54.

6 Hawton K, van Heeringen K. Suicide. Lancet 2009;373:1372-81.

7 Chen YY, Wu KC-C, Yousuf S, Yip PSF. Suicide in Asia: opportunities and challenges. Epidemiol Rev 2012;34:129-44. 
8 Li Z, Page A, Martin G, Taylor R. Attributable risk of psychiatric and socioeconomic factors for suicide from individual-level, population-based studies: a systematic review. Soc Sci Med 2011;72:608-16.

9 Yoshimasu K, Kiyohara C, Miyashita K. Suicidal risk factors and completed suicide: meta-analyses based on psychological autopsy studies. Environ Health Prev Med 2008;13:243-56.

10 Rehkopf DH, Buka SL. The association between suicide and the socio-economic characteristics of geographical areas: a systematic review. Psychol Med 2006;36: 145-57.

11 Fukuda Y, Nakamura K, Takano T. Cause-specific mortality differences across socioeconomic position of municipalities in Japan, 1973-1977 and 1993-1998: increased importance of injury and suicide in inequality for ages under 75 . Int $\mathrm{J}$ Epidemiol 2005;34:100-9.

12 Platt S. Inequalities and suicide behaviour. In: O’Connor RC, Platt S, Gordon J, editors. International Handbook of Suicide Prevention: Research, Policy and Practice. Malden, MA: John Wiley \& Sons, 2011: 211-34.

13 Suzuki E, Kashima S, Kawachi I, Subramanian SV. Social and geographical inequalities in suicide in Japan from 1975 through 2005: a census-based longitudinal analysis. PLoS One 2013;8:e63443.

14 Ministry of Health, Labour and Welfare, Japan: Report of Vital Statistics: Occupational and Industrial Aspects. Available at: http://www.mhlw.go.jp/english/ database/db-hw/orvf.html (20 September 2013, date last accessed).

15 Ministry of Health, Labour and Welfare, Japan: Outline of Vital Statistics in Japan. Available at: http://www.mhlw.go.jp/english/database/db-hw/outline/index.html (20 September 2013, date last accessed).

16 Statistics Bureau, Ministry of Internal Affairs and Communications, Japan: Japan Standard Occupational Classification. Available at: http://www.stat.go.jp/english/ index/seido/shokgyou/index-co.html (20 September 2013, date last accessed).

17 Statistics Bureau, Ministry of Internal Affairs and Communications, Japan: Population Census. Available at: http://www.stat.go.jp/english/data/kokusei/index. htm (20 September 2013 date last accessed).

18 Statistics Bureau, Ministry of Internal Affairs and Communications, Japan: National Survey of Family Income and Expenditure. Available at: http://www.stat.go.jp/ english/data/zensho/index.html (20 September 2013 date last accessed).

19 Raudenbush SW, Bryk AS. Hierarchical Linear Models: Applications and Data Analysis Methods, 2nd edn. Thousand Oaks, CA: Sage Publications, 2002.

20 Subramanian SV, Duncan C, Jones K. Multilevel perspectives on modeling census data. Environment Planning A 2001;33:399-417.

21 Merlo J, Yang M, Chaix B, et al. A brief conceptual tutorial on multilevel analysis in social epidemiology: investigating contextual phenomena in different groups of people. J Epidemiol Community Health 2005;59:729-36.

22 Merlo J, Ohlsson H, Lynch KF, et al. Individual and collective bodies: using measures of variance and association in contextual epidemiology. J Epidemiol Community Health 2009;63:1043-8.
23 Riva M, Gauvin L, Barnett TA. Toward the next generation of research into small area effects on health: a synthesis of multilevel investigations published since July 1998. J Epidemiol Community Health 2007;61:853-61.

24 Næss $\varnothing$, Leyland AH. Analysing the effect of area of residence over the life course in multilevel epidemiology. Scand J Public Health 2010;38:119-26.

25 Rasbash J, Browne WJ, Healy M, et al. MLwiN Version 2.27. Centre for Multilevel Modelling, University of Bristol, 2013.

26 Browne WJ. MCMC Estimation in MLwiN version 2.26. Centre for Multilevel Modelling, University of Bristol, 2012.

27 Larsen K, Merlo J. Appropriate assessment of neighborhood effects on individual health: integrating random and fixed effects in multilevel logistic regression. Am J Epidemiol 2005;161:81-8.

28 Cabinet Office, Government of Japan: Prefectural Accounts. Available at: http:// www.esri.cao.go.jp/jp/sna/sonota/kenmin/kenmin_top.html (in Japanese) (20 September 2013, date last accessed).

29 Wilkinson RG, Pickett KE. Income inequality and population health: a review and explanation of the evidence. Soc Sci Med 2006;62:1768-84.

30 Chen J, Choi YJ, Sawada Y. How is suicide different in Japan? Japan World Econ 2009;21:140-50.

31 Inagaki K. Income inequality and the suicide rate in Japan: evidence from cointegration and LA-VAR. J Appl Econ 2010;13:113-33.

32 Cummins S, Macintyre S, Davidson S, Ellaway A. Measuring neighbourhood social and material context: generation and interpretation of ecological data from routine and non-routine sources. Health Place 2005;11:249-60.

33 Kelly BD, Davoren M, Mhaoláin ÁN, et al. Social capital and suicide in 11 European countries: an ecological analysis. Soc Psychiatry Psychiatr Epidemiol 2009;44:971-7.

34 Patel V. Building social capital and improving mental health care to prevent suicide. Int J Epidemiol 2010;39:1411-2.

35 Okamoto M, Kawakami N, Kido Y, Sakurai K. Social capital and suicide: an ecological study in Tokyo, Japan. Environ Health Prev Med 2013;18:306-12.

36 Hasegawa T. Japan: historical and current dimensions of health and health equity. In: Evans T, Whitehead M, Diderichsen F, et al, editors. Challenging Inequities in Health: From Ethics to Action. New York, NY: Oxford University Press, 2001: 90-103.

37 Tøllefsen IM, Hem E, Ekeberg Ø. The reliability of suicide statistics: a systematic review. BMC Psychiatry 2012;12:9.

38 Hendin H, Vijayuakumar L, Bertolote JM, et al. Epidemiology of suicide in Asia. In: Hendin H, Phillips MR, Vijayakumar L, et al, editors. Suicide and Suicide Prevention in Asia. Geneva, Switzerland: World Health Organization, 2008: 7-18.

39 DeJong TM, Overholser JC, Stockmeier CA. Apples to oranges?: A direct comparison between suicide attempters and suicide completers. J Affect Disord 2010;124:90-7.

40 Fushimi M, Sugawara J, Saito S. Comparison of completed and attempted suicide in Akita, Japan. Psychiatry Clin Neurosci 2006;60:289-95. 